\title{
1,2-Diacetates by epoxide ring opening promoted by erbium(III) triflate
}

\author{
Renato Dalpozzo, ${ }^{\mathrm{a}}$ Antonio De Nino, ${ }^{\mathrm{a}}$ Monica Nardi, ${ }^{\mathrm{a}}$ Beatrice Russo, ${ }^{\mathrm{b}}$ and Antonio \\ Procopiob \\ ${ }^{a}$ Dipartimento di Chimica, Univesità della Calabria, Ponte Bucci, cubo 12C, 87030 Arcavacata \\ di Rende (Cs), Italy \\ ${ }^{b}$ Dipartimento di Scienze Farmaco-Biologiche, Università della Magna Graecia, Complesso \\ Ninì Barbieri, 88021 Roccelletta di Borgia (Cz), Italy \\ E-mail: dalpozzo@unical.it
}

\section{Dedicated to Professor Giuseppe Bartoli on his 65th birthday}

\begin{abstract}
Erbium triflate is able to afford vic-diacetates in better yields, lower catalyst amounts and shorter times than most of the reported methods. Therefore, the present procedure represents a valuable, general and environmentally benign procedure to prepare these compounds.
\end{abstract}

Keywords: Epoxide, erbium(III) triflate, nucleophile, ring opening, Lewis acid, catalysis

\section{Introduction}

Epoxides have been recognized among the most versatile intermediates in organic synthesis. They can be easily prepared and, due to their ring strain, which enhances their reactivity, they react with nucleophiles to highly regioselectively lead to ring-opened products. ${ }^{1}$ Among reactions involving epoxides three are worth noting: 1,2-diol preparation, which is one of the most useful reactions and the acetylation of alcohols, which is a fundamental process, providing a cheap and efficient means for protecting hydroxy frameworks; ${ }^{2} \beta$-hydroxy ethers synthesis, since they are important precursors for the preparation of $\alpha$-alkoxy ketones and acids; ${ }^{3} \beta$-amino alcohols preparation, because they are an important class of organic compounds being versatile intermediate for a vast range of biologically active natural products. ${ }^{4}$

Notwithstanding a wide choice of activators or promoters available for each of the abovecited transformations, many are associated with one or more drawbacks. They include the use of anhydrous solvents, moisture sensitive catalysts, expensive and/or hazardous reagents, strongly acidic conditions, extended reaction times, unsatisfactorily yields etc. Therefore, the 
development of simple and easily handling reagents, which are efficient and provide convenient procedures with high yields, is needed.

Among the reactions mentioned above, direct transformation of epoxides into 1,2-diacetates is a very important, but scarcely studied, reaction. In fact, if a plethora of methods are reported for the synthesis of $\beta$-hydroxy ethers and $\beta$-amino alcohols, only few methods lead to 1,2diacetates from epoxides involving the use of acetic anhydride with aluminosilicate, ${ }^{5}$ phosphorus $^{6}$ and boron ${ }^{7}$ compounds or sulfuric acid, ${ }^{8}$ and only two reports have a general value, ${ }^{5 b, 6 a}$ being the others limited in scope.

In the last years, the ongoing work in our laboratory was on the use of erbium(III) triflate as useful and environmentally friendly catalyst for many acid-catalyzed reactions. ${ }^{9}$ It should be noted that, among lanthanide triflates, erbium salt was the most neglected, notwithstanding it appears in good agreement with Kobayashi's relationship among catalytic activity / $\mathrm{K}_{\mathrm{h}} / \mathrm{WERC}$, having $\mathrm{pK}_{\mathrm{h}}=7.9$ and $\mathrm{WERC}=1.4 \times 10^{8} .{ }^{10}$

We were interested, among others, in Lewis acid catalyzed reactions of epoxides, ${ }^{11}$ and acetylation reactions, ${ }^{9 a}$ therefore it seemed obvious to investigate the use of this reagent for the efficient conversion of epoxide into 1,2-diacetates.

\section{Results and Discussion}

Table 1. Synthesis of vic-diacetates from epoxides and acetic anhydride in the presence of erbium(III) triflate $(0.1 \% \mathrm{~mol})$

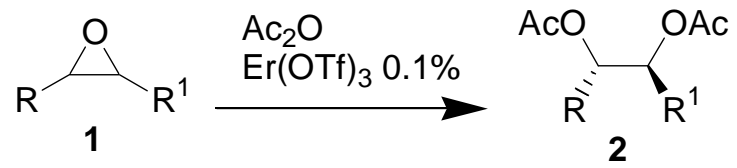

\begin{tabular}{|c|c|c|c|c|c|}
\hline Entry & Substrate & $\mathrm{R}$ and $\mathrm{R}^{1}$ & Time $(\mathrm{h})$ & Product & Yield $(\%)^{\mathrm{a}}$ \\
\hline 1 & $1 \mathrm{a}$ & & 0.25 & $2 a^{b}$ & 97 \\
\hline 2 & $1 b$ & $-\left(\mathrm{CH}_{2}\right)_{4-}$ & 3 & $2 \mathbf{b}$ & 93 \\
\hline 3 & 1c & $\mathrm{Bu}, \mathrm{H}$ & 1 & $2 c$ & $>99$ \\
\hline 4 & 1d & $\mathrm{CH}_{2} \mathrm{OH}, \mathrm{H}$ & 5 & $2 d^{c}$ & 60 \\
\hline 5 & 1e & $\mathrm{CH}_{2} \mathrm{OCH}_{3}, \mathrm{H}$ & 1 & $2 e$ & $>99$ \\
\hline 6 & 1f & $\left(\mathrm{CH}_{2}\right)_{2} \mathrm{CH}=\mathrm{CH}_{2}, \mathrm{H}$ & 1 & $2 f$ & 91 \\
\hline 7 & $1 g$ & & 6 & $2 g$ & 73 \\
\hline
\end{tabular}

${ }^{\text {a }}$ Isolated yields based on epoxides.

${ }^{\mathrm{b}}$ See ref. $9 \mathrm{c}$.

${ }^{\mathrm{c}}$ Peracetylated product was obtained 
The reactions were carried out in the presence of $0.1 \% \mathrm{~mol}$ of erbium(III) triflate as catalyst, by mixing together the epoxide and acetic anhydride. Since the only by-product is acetic acid from the excess of anhydride, these conditions are also environmentally benign. A control experiment showed that no reaction occurred in the absence of triflate. The results are collected in Table 1.

All reactions proceeded in good- to very high- yields, with the formation of only one diastereoisomer with the two acetoxy groups anti each other, in agreement with literature. ${ }^{5-8}$ The stereochemistry was demonstrated by prolonging the reaction time to remove the benzylidene protection in methyl 2,3-anhydro-4,6-O-benzyliden- $\alpha$-D-allopyranoside (1a), which was then quantitatively converted into peracetylated methyl- $\alpha$-D-glucose. In fact, we measured a coupling constant $\mathrm{J}_{\mathrm{H} 1-\mathrm{H} 2}=3.71$ in good agreement with the value found in the ${ }^{1} \mathrm{H}-\mathrm{NMR}$ spectrum of true peracetylated methyl $\alpha$-D glucose.

Aromatic epoxides cannot be converted into 1,2-diacetoxy derivatives. The reaction of styrene oxide in acetic anhydride afforded a 1:1 mixture of 1,2- and 2,2-diacetoxy-1phenylethanes, owing to the competitive epoxide rearrangement to aldehyde catalyzed by erbium triflate, ${ }^{11 \mathrm{~b}}$ followed by diacetoxy protection of the aldehyde. ${ }^{12}$ Attempts to avoid rearrangement were unsuccessful. The reaction was carried out either in dichloromethane or with cerium(III) triflate as catalyst, leading to $13 / 65$ and 45/56 1,2 vs. 2,2-diacetoxy-1-phenylethane ratios, respectively.

In order to show the merit of present work, the results from cyclohexene oxide (1b) and 1hexene oxide (1c) can be compared with the catalyst amount, the reaction time, and the yields reported in the other two general protocols. ${ }^{5 b, 6 a}$ Table 2 shows that erbium triflate is able to afford vic-diacetates in better yields, lower catalyst amounts, and shorter times than the most efficient reported method.

Table 2. Comparison of the of the effect of catalyst for vic-diacetate synthesis

\begin{tabular}{|c|c|c|c|c|c|}
\hline Product & Catalyst & Amount & Time & Yield $(\%)$ & Ref \\
\hline \multirow{3}{*}{ 1b } & $\operatorname{Er}(\mathrm{OTf})_{3}$ & $0.1 \%$ & 3 & 93 & - \\
\hline & $\mathrm{PBu}_{3}$ & $10 \%$ & $24^{\mathrm{a}}$ & 92 & $6 a$ \\
\hline & Zeolite HY & $0.5 \mathrm{~g}$ per $10 \mathrm{mmol}$ & 10 & 85 & $5 b$ \\
\hline \multirow{3}{*}{ 1c } & $\operatorname{Er}(\mathrm{OTf})_{3}$ & $0.1 \%$ & 1 & $>99$ & - \\
\hline & $\mathrm{PBu}_{3}$ & $10 \%$ & $24^{\mathrm{a}}$ & 96 & $6 a$ \\
\hline & Zeolite HY & $0.5 \mathrm{~g}$ per $10 \mathrm{mmol}$ & 9.5 & 95 & $5 b$ \\
\hline
\end{tabular}

${ }^{\text {a }}$ Reaction time is not reported. One day is the requested time for $N$-tosylaziridine ring opening

Although we never conducted a complete mechanistic investigation on the reaction, a tentative explanation is depicted in Scheme 1. 


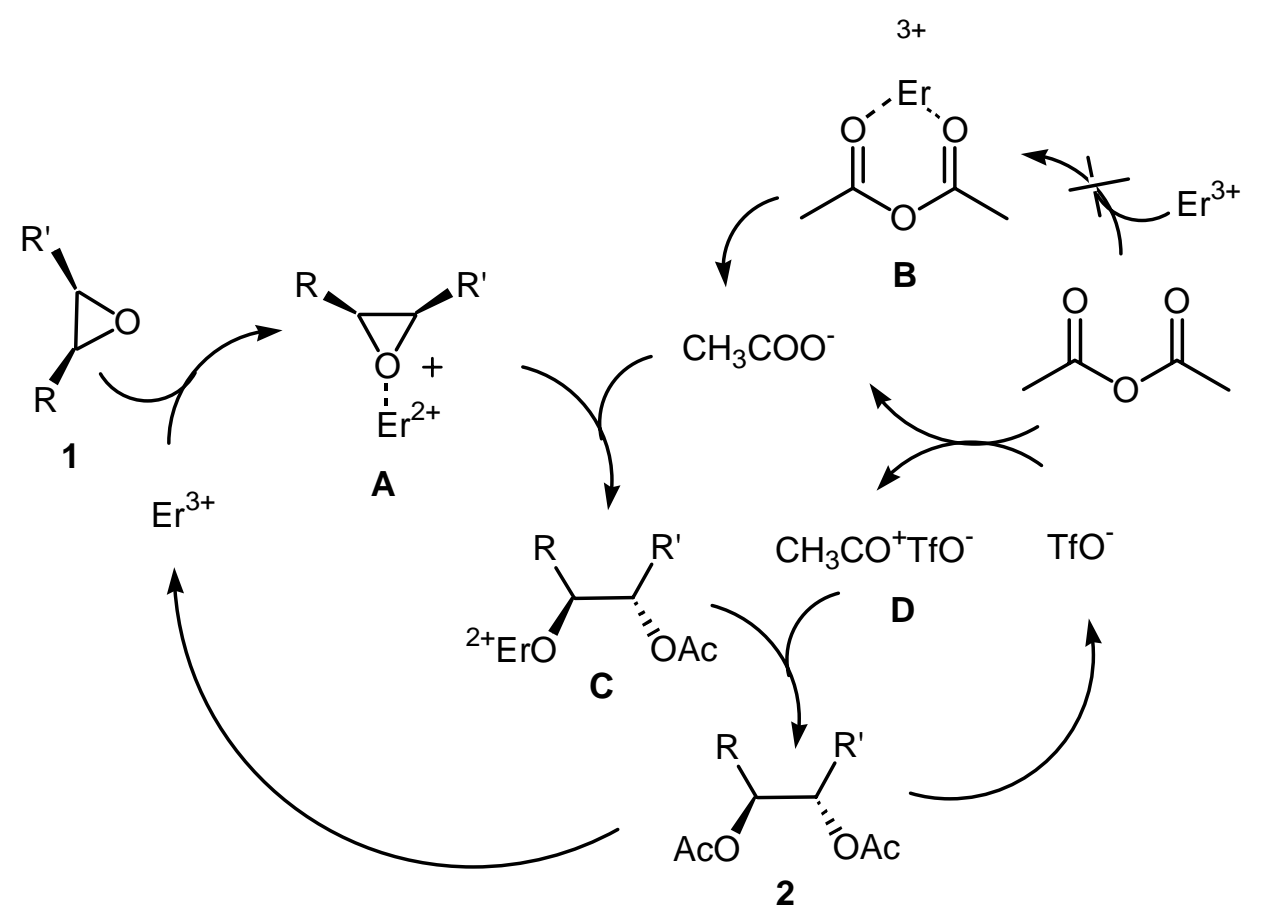

Scheme 1. Tentative mechanism for the reaction.

There are, in principle, two coordination sites for the erbium ion: the epoxide oxygen atom or the carbonyl groups of acetic anhydride, giving rise to complexes $\mathbf{A}$ and $\mathbf{B}$ respectively (Scheme 1). Both can give a catalytic loop able to reach the products. In our previous works we had evidences of coordination to both compounds. ${ }^{9 a, 11}$ However, since, in aryl epoxides, the rearrangement is independent of the presence of acetic anhydride, and it occurs at a rate comparable to the ring-opening, it allows us to think that $\mathbf{A}$, rather than $\mathbf{B}$, is the first intermediate of the reaction. The activated epoxide ring (A) is then opened from the opposite side by acetate ion, which acts as a nucleophile, giving intermediate $\mathbf{C}$. Acetate ion is released by interaction between the anhydride and triflate ion. Formation of a mixed anhydride such as D, which releases carboxylate salt, has already been invoked in the reaction of triflates and anhydrides. ${ }^{13}$ Moreover, tributylphosphine is reported to activate acetic anhydride to form a salt which attacks epoxide to give the ring opened product. ${ }^{6 a}$ Finally, coupling between $\mathbf{C}$ and $\mathbf{D}$ leads to catalyst re-generation and product formation.

In a fashion of a preferential coordination to epoxide oxygen, ring opening must occur with any nucleophile. In order to confirm this hypothesis, we performed epoxide ring opening with an alcohol and an amine. Methanol and aniline were chosen as typical examples of these classes of compounds.

Actually, methanol opened cyclohexene oxide faster than acetic anhydride (1h vs. $3 \mathrm{~h}$ ), leading to trans-2-methoxycyclohexanol in almost quantitative yields. Ring opening with methanol is so fast that rearrangement of styrene oxide is prevented and also 2-phenyl-2methoxyethanol is recovered in almost quantitative yield. Formation of this product rather than 
its regioisomer 1-phenyl-2-methoxyethanol, however, is not conclusive evidence of an acidcatalyzed reaction, which would prove a metal-epoxide interaction. In fact, it is known that anion can attack styrene oxide at the more substituted carbon terminus. ${ }^{14}$ On the other hand, these findings demonstrate that anhydride cleavage is the rate-determining step of the reaction.

Finally, a further reaction between styrene oxide and aniline was performed and the expected 2-( $N$-phenylamino)-2-phenylethanol was obtained in 95\% yield.

\section{Conclusions}

Erbium(III) triflate provides the first really general method of direct conversion of epoxides into 1,2-diacetates, providing a cheap, efficient, general and environmentally benign mean for protecting diol frameworks. It is able to afford vic-diacetates in better yields, with lower catalyst amounts and shorter times than most of the reported methods. ${ }^{5-8}$ The present procedure does not need sophisticated equipment, and uses a non-toxic ${ }^{15}$ and non-explosive catalyst. The catalyst can be easily and consistently recovered, and therefore there is negligible release into the environment. $^{16}$

Finally, studies are in progress in our laboratory to extend this reaction to other nucleophiles, prompted by the preliminary results reported here with methanol and aniline.

\section{Experimental Section}

General Procedures. ${ }^{1} \mathrm{H}-\mathrm{NMR}$ and ${ }^{13} \mathrm{C}-\mathrm{NMR}$ spectra were recorded with a Bruker WM300 instrument, at $300 \mathrm{MHz}$ and $75 \mathrm{MHz}$ respectively. Reactions were monitored by a GC-MS Hewlett-Packard workstation, formed by a GC-HP 6890 (30-m HPS capillary column, 1 mL/min He as carrier gas) and by an HP 5973 mass detector. Commercial products (Aldrich or Fluka) were used without further purification.

General procedure for epoxide ring opening with acetic anhydride. A solution of epoxide (1a-h) $(5 \mathrm{mmol})$ in acetic anhydride $(1 \mathrm{~mL})$ was stirred and $\operatorname{Er}(\mathrm{OTf})_{3}(3 \mathrm{mg}, 0.005 \mathrm{mmol}, 0.1$ mol.\%) was added at room temperature. The reaction progress was monitored by TLC. After the appropriate time (Table 1) a 10\% solution of $\mathrm{Na} 2 \mathrm{CO} 3$ was added and the mixture was extracted with ether $(2 \times 2 \mathrm{~mL})$. The combined organic layers were dried $\left(\mathrm{Na}_{2} \mathrm{SO}_{4}\right)$. The solvents were removed on a rotary evaporator to give the corresponding vic-diacetates (2). Unless otherwise specified, all products were identified by comparison of their EI-MS and ${ }^{1} \mathrm{H}$ NMR spectral data with those of authentic compounds and literature reported data: $\mathbf{2 a},{ }^{9 \mathrm{c}} \mathbf{2} \mathbf{b}, \mathbf{2} \mathbf{c}, \mathbf{2} \mathbf{d},{ }^{5 \mathrm{~b}} \mathbf{2} \mathbf{e},{ }^{17} \mathbf{2} \mathbf{f}, \mathbf{2 g}^{18}$

Reaction of cyclohexene oxide (1b) and styrene oxide with methanol. A solution of $\mathbf{1 b}(0.98$ $\mathrm{g}, 10 \mathrm{mmol})$ in methanol $(2 \mathrm{~mL})$ was stirred and $\operatorname{Er}(\mathrm{OTf})_{3}(6 \mathrm{mg}, 0.001 \mathrm{mmol}, 0.1 \mathrm{~mol} \%$ ) was 
added at room temperature. The reaction progress was monitored by TLC. After $1 \mathrm{~h}$, a $10 \%$ solution of $\mathrm{Na} 2 \mathrm{CO} 3$ was added and the mixture was extracted with ether $(2 \times 2 \mathrm{~mL})$. The combined organic layers were dried $\left(\mathrm{Na}_{2} \mathrm{SO}_{4}\right)$. The solvents were removed on a rotary evaporator to give trans-2-methoxycyclohexanol in almost quantitative yield, which was recognized by comparison of its spectroscopic data with the literature. ${ }^{19}$

The reaction of styrene oxide $(1.20 \mathrm{~g}, 10 \mathrm{mmol})$ was carried out under the same reaction conditions. After $0.5 \mathrm{~h}$, a $10 \%$ solution of $\mathrm{Na} 2 \mathrm{CO} 3$ was added and the mixture was extracted with ether $(2 \times 2 \mathrm{~mL})$. The combined organic layers were dried $\left(\mathrm{Na}_{2} \mathrm{SO}_{4}\right)$. The solvents were removed on a rotary evaporator to give 2-phenyl-2-methoxyethanol in almost quantitative yield, which was recognized by comparison of its spectroscopic data with literature. ${ }^{20}$

Reaction of styrene oxide with aniline. The reaction of styrene oxide $(1.20 \mathrm{~g}, 10 \mathrm{mmol})$ and aniline $(1 \mathrm{~mL})$ was stirred and $\operatorname{Er}(\mathrm{OTf})_{3}(6 \mathrm{mg}, 0.001 \mathrm{mmol}, 0.1 \mathrm{~mol} \%)$ was added at room temperature. After $0.5 \mathrm{~h}$, a $10 \%$ solution of $\mathrm{Na}_{2} \mathrm{CO}_{3}$ was added and the mixture was extracted with ether $(2 \times 2 \mathrm{~mL})$. The combined organic layers were dried $\left(\mathrm{Na}_{2} \mathrm{SO}_{4}\right)$. The solvents were removed on a rotary evaporator to give 2-( $N$-phenylamino)-2-phenylethanol in $95 \%$ yield, which was recognized by comparison of its spectroscopic data with the literature. ${ }^{21}$

\section{References}

1. Carey F. A.; Sundberg R. J. Advanced Organic Chemistry, $4^{\text {th }}$ Edn.; Kluwer: New York, 2001, Part B, chapter 12.2.3.

2. Green T. W.; Wuts P. G. M. Protective Groups in Organic Synthesis, $3^{\text {rd }}$ Edn.; Wiley Interscience: New York, 1999, pp 150-160.

3. (a) Yadav, J. S.; Reddy B. V. S.; Harikishan, K.; Madan, C.; Narsaiah, A. V. Synthesis 2005, 2807 and literature cited therein. (b) Smith, J. C. Synthesis 1984, 629.

4. (a) Zhao P. Q.; Xu, L. W.; Xia C. G. Synlett 2004, 846 and literature cited therein. (b) Mirkani, V.; Tangestaninejad, S.; Yadollahi, B.; Alipanah, L. Catal. Lett. 2005, 101, 93 and reference cited therein.

5. (a) Tatarova, L.E.; Korchagina, D.V.; Volko, K. P.; Salakhutdinov, N. F.; Barkhash V. A. Russ. J. Organ. Chem. 2003, 39, 1076; Chem. Abst. 2004, 140, 271015. (b) Ramesh, P.; Reddy, V. L. N.; Venugopal, D.; Subrahmanyam, M.; Venkateswarlu, Y. Synthetic Commun. 2001, 31, 2599.

6. (a) Fan, R. H.; Hou, X. L. Tetrahedron Lett. 2003, 44, 4411. (b) Perri, S. T.; Falling, S. N. U. S. Patent 5,663,422, 1996; Chem. Abst. 1997, 127, 220395.

7. (a)Yanachkov, I. B.; Yankov, L. K. Dokladi Bulg. Akad. Nauk. 1997, 50, 29; Chem. Abst. 1999, 131, 199409. (b) Sarmah, P.; Baruah, R. N.; Sharma, R. P. Indian J. Chem. Sect BOrg. Chem. Incl. Med. Chem. 1985, 24B, 201.

8. Malinowskii M. S.; Yudasina A. G.; Skrodoskaya T. S.; Larionova, V. G. Ukr. Khim. Zh. 1967, 33, 598; Chem. Abst. 1968, 68, 104850. 
9. (a) Procopio, A.; Dalpozzo, R.; De Nino, A.; Maiuolo, L.; Russo, B.; Sindona, G. Adv. Synth. Catal. 2004, 346, 1465. (b) Dalpozzo, R.; De Nino, A.; Maiuolo, L.; Nardi, M.; Procopio, A.; Tagarelli, A. Synthesis 2004, 496. (c) Procopio, A.; Dalpozzo, R.; De Nino, A.; Maiuolo, L.; Nardi, M.; Romeo, G. Org. Biomol. Chem. 2005, 4129. (d) Procopio, A.; Dalpozzo, R.; De Nino, A.; Nardi, M.; Russo, B.; Tagarelli A. Synthesis, 2006, in press.

10. (a) Kobayashi, S.; Sugiura, M.; Kitagawa, H.; Lam, W.W.-L. Chem. Rev. 2002, 102, 2227. (b) Kobayashi, S.; Menabe, K. Acc. Chem. Res. 2002, 35, 209. (c) Kobayashi, S.; Nagayama, S.; Busujima, T. J. Am. Chem. Soc. 1998, $120,8287$.

11. (a) Procopio, A.; Dalpozzo, R.; De Nino, A.; Maiuolo, L.; Nardi, M.; Russo B. Adv. Synth. Catal. 2005, 347, 1447. (b) Procopio, A.; Dalpozzo, R.; De Nino, A.; Nardi, M.; Sindona, G.; Tagarelli A. Synlett 2004, 2633.

12. Dalpozzo, R.; De Nino A.; Maiuolo, L.; Nardi, M.; Procopio, A.; Russo B.; Tagarelli A. Arkivoc, 2006, (vi) submitted

13. (a) Ghosh, R.; Maiti, S.; Chakraborty, A.; Halder R. J. Mol. Catal. A: Chem. 2004, 215, 49.

(b) Dumeunier, R.; Marko, I. E. Tetrahedron Lett. 2004, 45, 825.

14. (a) Epifani, E.; Florio, S.; Gasparri Fava, G. Tetrahedron 1990, 46, 8169. (b) Cundari, S.; Dalpozzo, R.; De Nino, A.; Procopio, A.; Sindona, G.; Athanassopulos, K. Tetrahedron 1999, 55, 10155.

15. $\mathrm{LD}_{50}$ of erbium salts is $4417 \mathrm{mg} / \mathrm{Kg}$ against $4000 \mathrm{mg} / \mathrm{Kg}$ of $\mathrm{NaCl}$.

16. Scaling-up the reaction, catalyst is very likely recovered in higher yields with respect our experiments, where it is recovered more than $90 \%$. To recover the catalyst, the work-up aqueous phase can be evaporated under reduced pressure to furnish the $\operatorname{Er}($ III) salt as a pale pink solid, which can be reused after drying overnight over $\mathrm{P}_{2} \mathrm{O}_{5}$. The purity of recovered Er(OTf $)_{3}$ was confirmed by comparison with the IR spectrum of commercial product.

17. Poppe, L.; Novak, L.; Kajtar-Peredy, M.; Szantay, C.; Tetrahedron: Asymmetry 1993, 4, 2211

18. Yoshimori, Y.; Cho, C. S.; Uemura, S. J. Organomet. Chem. 1995, 487, 55.

19. Battioni J. P.; Chodkiewicz, W. Bull. Soc. Chim. Fr. 1977, 320.

20. Iranpoor N.; Salehi, P.; Synthesis 1994, 1152.

21. Sabitha, G.; Reddy, G. S. K. K.; Reddy, K. B.; Yadav J. S. Synthesis 2003, 2298. 